\title{
A DIVISÃO HISTÓRICA JAPONESA
}

\author{
Beatriz Shizuko Takenaga
}

\section{A IMPORTÂNCIA DA PERIODIZAÇÃo}

Para se estudar a história de um país, não se pode negar que é fundamental conhecer a sua periodização, ou seja,-o seu sistema de divisão histórica. No caso do estudo da História do Japão, negligenciar o sistema de periodização poderia prejudicar consideravelmente o prosseguimento de um trabalho de pesquisa nessa área. Tentaremos pois, no presente trabalho demonstrar que o conhecimento da periodização japonesa é primordial para os estudos japoneses.

\section{ERA OU PERÍODO?}

Em Geologia, costuma-se dividir os espaços de tempo em eras e períodos. Emprega-se o termo "era" para indicar um espaço de tempo mais abrangente e o termo "período" para indicar um espaço de tempo menor. Por exemplo: a era proterozóica subdivide-se em: a) período azóico; b) período pré-cambriano; a era paleozóica subdivide-se em outros 5 ou 6 períodos e assim por diante.

Na história japonesa, existem também a divisão maior e outra menor. Como não existe exatamente uma unificação no que se refere à tradução de termos japoneses relativos a essa divisões, utilizaremos a terminologia geológica acima citada, ou seja, para as divisões maiores, empregaremos o termo "era" e para as divisões menores, o termo "período"

\subsection{As Eras}

Começando pelas divisões maiores, a história japonesa é usualmente dividida da seguinte forma:

1) Genshi Jidai "Era primitiva" - data de aproximadamente 9.000 anos atrás.

2) Kodai "Antiguidade" ou "Era Clássica" Tem início por volta do século 4 da era cristã e vai até o século 12.

3) Chûsei(1) "Idade Média" ou "Tempos Medievais" Inicia-se no sé-

(1) O acento circunflexo em algumas sílabas de palavras japonesas do presente trabalho, indica que a sílaba é longa. 
culo 12 terminando na segunda metade do século 16.

4) Kinsei - pelas características do sistema político vigente nessa era, podemos considerar o Kinsei como uma 2a fase da época feudal que teve início no Chûsei. Tem início na 2a metade do século 16 e termina na 2a - metade do século 19.

5) Kindai "Era Moderna" - inicia-se na 2a - metade do século 19 e o fim da 2a - Guerra Mundial marca também o término dessa era.

6) Gendai "Era Contemporânea" - inicia-se a partir do término da 2a Guerra Mundial e continua até os dias atuais.

\subsection{Os Períodos}

Cada uma das eras acima citadas, pode ser subdividida em espaços de tempo menores que chamaremos de períodos:

1) Genshi Jidai

a) Kyûsekki Jidai - corresponde ao período paleolítico.

b) Jômon Jidai "Período Jômon" - é difícil determinar o início desse período pois há teorias que dizem que teve início há cerca de 9.000 anos atrás, enquanto que há outras teorias que falam em 5.000 anos atrás. O término do Jômon Jidai é entre o ano 300 e 200 A.C.

c) Yayoi Jidai "Período Yayoi" - período compreendido entre o século 3 A.C. e o século 3 D.C. aproximadamente.

2) Kodai

a) Yamato Jidai "Período Yamato" - período que se inicia no século 4 e termina no ano 645.

b) Nara Jidai "Período Nara" - $710 \sim 784$.

c) Heian Jidai "Período Heian" - $794 \sim 1.185$

3) Chûsei

a) Kamakura Jidai "Período Kamakura" - $1185 \sim 1333$.

b) Muromachi Jidai "Período Muromachi" - $1338 \sim 1573$. Aqui faz-se necessário mencionar mais dois períodos que podem ser considerados como subdivisões do Período Muromachi. São eles:

b-1) Nanbokuchô Jidai "Período Nanbokuchô" - $1333 \sim 1392$.

b-2) Sengoku Jidai "Período Sengoku" - $1467 \sim 1568$.

4) Kinsei

a) Azuchi-Momoyama Jidai "Período Azuchi-Momoyama 1568 
1600 (ou 1603).

b) Edo Jidai "Período Edo" - 1600 (ou 1603) 1867

5) Kindai

a) Meiji Jidai "Período Meiji" - $1868 \sim 1912$.

b) Taishô Jidai "Período Taishô - 1912 1925.

c) Shôwa Jidai "Período Shôwa" - 1926 1945.

\section{6) Gendai}

- Shôwa Jidai "Período Shôwa" - a partir do término da 2a - Guerra Mundial até os dias atuais.

\section{Visão geral de CADA Período}

Para facilitar a compreensão dos critérios de divisão histórica, passaremos a expor sobre alguns fatos e personagens que marcaram cada período.

\subsection{Genshi Jidai}

\subsubsection{Kyûsekki Jidai}

É o chamado Período Paleolítico ou Idade da Pedra Lascada. Graças ao desenvolvimento dos estudos arqueológicos, pôde-se constatar evidências da presença do homem no território japonês nesse período, embora as informações a esse respeito ainda sejam muito reduzidas.

\subsubsection{Jômon Jidai}

Neste período, o homem vivia da caça, pesca e coleta de frutos. Por meio de escavações, foram encontrados alguns túmulos da época. DetaIhes referentes aos objetos encontrados nesses túmulos, ao modo como os mortos eram enterrados e às dimensões desses túmulos, levaram os especialistas a concluir que nessa época nao havia diferenciação social.

\subsubsection{Yayoi Jidai}

Neste período, o homem utiliza práticas agrícolas pela primeira vez, aprendendo também a usar o metal, que veio da China, via arquipélago coreano.

Com $n$ início da produção agrícola, alguns indivíduos passam a produzir mais que outros, o que cria condições para o acúmulo de riquezas. Surgem as diferenças entre ricos e pobres e os ricos passam a deter o poder político. A partir das propriedades destes, surgem "pequenas nações" que segundo documentos chineses, ultrapassavam o número de 100 por volta do século 2 A.C. 


\subsection{Kodai}

\subsubsection{Yamato Jidai}

Assim denominado porque a sede política ficava em Yamato.

Segundo o Gishi, livro que narra a história de $\boldsymbol{G i}$, uma das dinastias chinesas do século 3 , o país de $\boldsymbol{W a}$ (nome pelo qual o Japão era conhecido entre os chineses) estava mergulhado em grandes conflitos internos no fim do século 2, mas no século 3, uma mulher, Himiko, é escolhida para reinar sobre cerca de 30 "pequenas nações", sendo que a sede política era a "nação" de Yamataikoku.

A partir do reinado de Himiko, o Japão passou por um processo de unificação e na metade do século 4, o país já tendo sua capital em Yamato, teria completado sua unificação.

Ainda neste período, entre os séculos 5 e 6, surge um sistema de governo, conhecido como Shisei Seido, "Sistema Shisei", no qual as famílias mais poderosas ocupavam altos cargos no governo central, exercendo o poder ao lado do Imperador.

Figura de destaque deste período foi Shôtoku Taishi "Príncipe Shôtoku", que governou o Japão a partir do ano de 593 como Sessho da Imperatriz Suiko. A função do Sessho era governar o país como representante do Imperador. A Imperatriz Suiko ascendeu ao trono no ano de 592, mas foi Shôtoku Taishi quem realmente exerceu a função de governante.

A atuação de Shôtoku Taishi na área cultural foi notável, mas politicamente limitou-se a ter ideais. Contudo mais tarde, o Príncipe Nakanoôe materializou os ideais políticos de Shôtoku Taishi, trabalhando no movimento que deu origem ao Taika-no Kaishin "Reforma Taika", em 645. Embora esta data seja normalmente tida como a data que marca o fim do Período Yamato, o espaço de tempo que vem a seguir, até o ano de 701 também costuma ser incluído dentro deste período.

\subsubsection{Nara Jidai}

Este período é assim chamado porque a capital era Heijôkyô, que ficava em Nara. Cunhou-se a primeira moeda de cobre e colocou-se em prática o Taihô Ritsuryô "Código de Leis Taihô"

Esta foi uma época de grande influência chinesa principalmente na área cultural, já que o Japão mantinha um ativo intercâmbio com a Dinastia Tô, que exercia o poder na China na época.

O fim do Período Nara foi marcado por intensa rivalidade entre as famílias da aristocracia e por um vertiginoso revezamento no poder.

\subsubsection{Heian Jidai}

No plano político podemos destacar aqui duas formas de governo bastante peculiares: o Sekkan Seiji e o Insei. 
O Sekkan Seiji foi um sistema que vigorou entre os séculos 9 e 11. Teve início em uma certa época quando subiu ao trono um imperador que ainda não atingira a maioridade. Por este motivo, alguém foi encarregado de representar o Imperador no governo até este atingir a idade adulta. Esta pessoa recebia o título de Sesshô.

Quando o Imperador chegou à idade adulta, uma outra pessoa, recebendo o título de Kanpaku, governava em seu lugar. Destas duas palavras, Sesshô e Kanpaku é que se originou o nome Sekkan Seiji, uma forma de governo em que o poder real era exercido pelo Sesshô e pelo Kanpaku, sendo que o Imperador permanecia apenas como uma figura decorativa. John Whitney Hall fez um comentário a respeito da irregularidade desta situação:

Not only was the entronement of a minor considered irregular, but this was the first time a person other than an Imperial Prince had held the post of regent. Even more irregular, was the continuation of the regency after the emperor had come of age. ${ }^{2}$ )

Quanto ao Insei, teve início quando o Imperador Shirakawa, que subiu ao trono em 1072, abdicou em favor do Imperador Horikawa, no ano de 1086. Depois deste houve mais dois imperadores. Todos eles governaram o país como Jôkô ou Hôô, títulos honoríficos atribuídos aos imperadores que subiram ao trono depois da abdicação. A essa forma de governo em que após a abdicação do imperador, o poder ficou nas mãos do Jôkô e do Hôô, é que se deu o nome de Insei.

Posteriormente houve a ascensão política do clã dos Taira. A queda do clã Taira marca o término do Período Heian.

\subsection{Chûsei}

\subsubsection{Kamakura Jidai}

No fim do século 12, da disputa entre os clãs Taira e Minamoto estes saem vencedores. O responsável pela queda dos Taira, Minamoto-no Yoritomo, funda o shogunato em Kamakura, sede política da classe guerreira.

Até o ano 1221 havia a coexistência de duas sedes políticas: uma em Kyôto, onde estava a Corte Imperial, e outra em Kamakura. Após um incidente, no qual houve uma tentativa malograda de derrubar o shogunato, o controle político passou a ser monopolizado pela classe guerreira.

(2) HALL, John Whitney. Japan - from Prehistory to Modern times, p. 65. 


\subsubsection{Nanbokuchô Jidai}

Depois da queda do Shogunato Kamakura, o Imperador Godaigo estabeleceu em Kyôto uma nova forma de governo, almejando a restauração do Sistema Ritsuryô e o estabelecimento de um sistema administrativo centralizado na Corte Imperial. Esta fase ficou conhecida como Kenmu no Shinsei (1333 1336), fase esta que costuma ser incluída no Período Nanbokuchô, embora alguns autores a considerem como um período distinto.

No Período Nanbokuchô havia também duas sedes: uma em Kyôto, denominada Hokuchô e outra em uma localidade chamada Yoshino que passou a ser denominada Nanchô. Da junção dos ideogramas Nan de Nanchô e Hoku de Hokuchô, é que surgiu o nome Nanbokuchô.

Nesta época estabeleceu-se também o Shogunato Muromachi.

Havia antagonismo entre o Nanchô e o Hokuchô, assim como também havia antagonismo entre os elementos do Shogunato Muromachi, o que deu origem à lutas intermináveis.

Entretanto tudo acabou com a unificação de Nanchô e Hokuchô e o Shogunato Muromachi acabou absorvendo o poder da Corte.

\subsubsection{Muromachi Jidai}

Em 1336, Ashikaga Takauji estabelece em Kyôto, o Hokuchô. No mesmo ano funda o Shogunato Muromachi.

A sede do governo ficava em Muromachi, localidade de Kyôto. A organização administrativa do Shogunato Muromachi assemelhava-se à organização do Shogunato Kamakura.

Os distúrbios ocorridos durante o Período Nanboku fizeram com que o Shogunato munisse de considerável autoridade, os Shugo, indivíduos encarregados da segurança. Além de controlar a agitação dos agricultores e de subjugar os guerreiros das províncias, os Shugo realizavam a coleta de impostos que eram cobrados sobre o comércio e sobre as atividades dos usuários.

No Período Nanbokuchô, a fim de financiar as despesas de guerra, o Shogunato conferiu autoridade aos Shugo para dispor de metade dos impostos sobre as terras, quantia que deveria ser destinada ao provimento de alimentos para os soldados. Os Shugo, valendo-se dessa autoridade, apoderavam-se dessas terras e até de possessões do governo. Eles passaram a ser conhecidos como Shugo Daimyô (Daimyô "Senhor Feudal").

Devido ao controle obtido pelos Shugo, o Shogunato enfrentou muitos problemas, perdendo gradualmente sua força.

\subsubsection{Sengoku Jidai}

Do ponto de vista político e militar, foi um período no qual não ha- 
via unidade no país que se via assolado por constantes distúrbios.

Percebendo o enfraquecimento do poder do Shogunato Muromachi, alguns daimyô passaram a exercer a lei do mais forte, ou seja, os membros de classes inferiores eliminavam os de classes superiores a fim de se apoderarem de seus cargos. Além disso dedicavam-se à expansão de seus domínios almejando o controle total sobre a nação.

Os Shugo Daimyô que estavam no poder, foram derrubados por seus vassalos, fazendo surgirem daí os chamados Sengoku Daimyô.

Pode se afirmar que neste período os momentos de paz eram quase inexistentes; em todo o país reinavam a anarquia e a pobreza e este estado de coisas só se alteraria após a ação de Oda Nobunaga, que iniciou a pacificação e a unificação do Japão.

\subsection{Kinsei}

\subsubsection{Azuchi-Momoyama Jidai}

É a época em que Oda Nobunaga e Toyotomi Hideyoshi detiveram o poder. Nobunaga e Hideyoshi tinham seus castelos nas localidades de Azuchi e Fushimi, que mais tarde passou a se chamar Momoyama, daí o nome do período.

O sistema de poder descentralizado do Período Sengoku é reajustado e estabelece-se o Bakuhan Taisei, um sistema feudal centralizado.

Entre os feitos de Nobunaga e Hideyoshi, podemos ressaltar o levantamento de terras realizado por Nobunaga com a finalidade de arrecadar taxas; Hideyoshi prosseguiu com este trabalho a partir de 1582, executando um levantamento em maior escala.

Além disso, Hideyoshi estabeleceu um sistema de classes, no qual fazia-se uma distinção rígida entre a classe dos agricultores e a dos guerreiros. Aliás uma das formas de se fazer essa distinção na prática era confiscar as armas dos indivíduos que não pertencessem à classe guerreira. Mais tarde uma outra lei estabeleceu 3 classes: a dos guerreiros, a dos comerciantes e a dos lavradores; segundo essa lei, não era permitido passar de uma classe para outra.

Do ponto de vista econômico, houve incentivo ao desenvolvimento do comércio e transportes, assim como também ao comércio exterior. $O$ contato com o exterior não mais se limitava à China e à Coréia. Em 1542, ainda no Período Muromachi, os japoneses tiveram o primeiro contato com os europeus. Eram os portugueses que vieram primeiro como comerciantes e depois como missionários cristãos. Mais tarde o cristianismo veio a ser proibido por Hideyoshi. 


\subsubsection{Edo Jidai}

Este é um período em que a consolidação do feudalismo se completa. Apresentou um desenvolvimento histórico único devido à reduzida influência estrangeira, consequiência da política isolacionista.

A sede política era em Edo, atual Tóquio. O fundador do shogunato Edo foi Tokugawa leyasu.

A produtividade agrícola nessa época aumentou; o comércio e a indústria tiveram um rápido desenvolvimento. Por um lado, a força dos comerciantes tornava-se cada vez maior. Por outro lado, os daimyô e os bushi "guerreiros" tornavam-se cada vez mais pobres.

\subsection{Kindai}

\subsubsection{Meiji Jidai}

O sistema feudal cai e o Japão parte em busca da construção de uma nação moderna. Com este objetivo realiza-se o Meiji Ishin "Reforma Meiji" ou "Restauração Meiji"

Tentando-se equiparar aos E.U.A. e aos países da Europa, o Japão começa a implantação do capitalismo, do sistema e da civilização do Ocidente.

Por volta de 1890, o Japão passa a ter um governo constitucional, pois no ano de 1889 é promulgada a constituição do Japão moderno.

Nesse período ocorrem também algumas crises nas relações exteriores, resultando em conflitos como a Guerra Sino-Japonesa (1894-1895) e a Guerra Russo-Japonesa (1904-1905).

O fim do período mostra também o lado negativo do desenvolvimento capitalista. Surgem problemas sociais e trabalhistas, aprofunda-se o antagonismo internacional e o Período Meiji termina em grave crise.

\subsubsection{Taishô Jidai}

Com a morte do Imperador Meiji em 1912, sobe ao trono o Imperador Taishô.

Esse período, mais especificamente a década de 20, foi um período de intensa consciência política do povo japonês, mas também foi um período em que a nação esteve envolvida em profundos problemas sociais e econômicos. No fim da década de 20 , a nação movia-se politicamente para dois extremos: direita e esquerda. Em um esforço para manter a unidade nacional, o Japão opta por seguir as tendências direitistas( 3 )

(3) HALL, John Whitney. Japan - from Prehistory to Modern times, p. 324. 


\subsubsection{Shôwa Jidai}

Após a 1- Guerra Mundial, as nações do regime capitalista viam-se em clima de constante depressão. Para escapar a essa situação, tentavase soluções diversas. A Alemanha e a Itália optam pelo nazismo e o fascismo. O Japão rapidamente une-se à Alemanha e a Itália na formação de uma aliança.

Em 1941, o Japão bombardeia Pearl Harbour, dando início à Guerra do Pacífico entre o Japão e as forças aliadas.

Em 14.08.1945, o governo japonês finalmente aceita render-se incondicionalmente de acordo com o que foi requerido pela declaração exposta na Conferência de Potsdam, tendo lugar em 2 de setembro do mesmo ano, a assinatura do documento de rendição.

\subsection{Gendai}

A partir de 1945, após a derrota, o Japão passou pelo período de ocupação das Forças Aliadas. $O$ país enfrentou muitas dificuldades, mas graças ao esforço de seu povo, recuperou-se sobretudo no plano econômico.

\section{OS CRITÉRIOS DA DIVISÃO HISTÓRICA}

Não é difícil identificar o critério estabelecido para a divisão em eras e a divisão em períodos.

Para a divisão em períodos, o Japão calcou-se no modelo chinês. Os chineses dividiam sua história conforme ocorria a mudança de dinastias; mudando a dinastia, o poder político obviamente passava para outras mãos e assim iniciava-se um novo período.

No Japão, a mudança de período indicava também uma alteração política; os nomes dos períodos de Yamato a Edo, são nomes de sedes de governo. Antes do Período Yamato, o Japão ainda não existia como nação propriamente dita, por isso os nomes Jômon e Yayoi pouco ou nada tem a ver com política mas sim com a cultura daquela época.

A partir do Período Meiji, os nomes dados aos períodos, não são mais os de sedes de governo mas sim nomes dos imperadores. De qualquer forma pode-se dizer que o critério político ainda se mantêm, embora tal afirmação seja discutível porque o poder real não é e nunca na verdade foi exercido pelo Imperador.

Se para a divisão em períodos, a história japonesa seguiu o modelo da divisão histórica chinesa, a divisão em eras está mais de acordo com o modelo ocidental. O critério político ainda é mantido pois na Era Kodai "Antiguidade", o Japão vivia sob o domínio da aristocracia; na Era Chûsei "Idade Média", temos a ascensão do sistema feudal que será con- 
solidado na Era Kinsei; na Era Kindai "Era Moderna", o capitalismo e o imperialismo são adotados; na Era Gendai, "Era Contemporânea", o Japão consolida-se como uma nação democrática e capitalista.

\section{NENGÔ OU GENGÔ}

Existe também um outro sistema de periodização, que originou-se também na China e que atualmente só o Japão utiliza: o nengô.

$\mathrm{Na}$ China, não havia uma data para se comemorar como o dia em que ela surgiu como nação; por não terem um ponto de partida, acabaram criando um sistema que permitia o início de um novo período cada vez que um novo soberano subia ao poder. $O$ ano seguinte à ascensão de um soberano passava a ser o $1^{\circ}$ ano de um novo período.

O Japão adotou esse sistema, batizando-o de Nengô ou Gengô. Os critérios para a divisão em nengô nem sempre estão relacionados com política; alguns estão relacionados a fatos econômicos ou culturais.

\section{TABELA 1 - NENGÔ ( 4 )}

\begin{tabular}{ll||} 
Calendário ocidental & Nengô \\
$645 \sim 650$ & Taika \\
$650 \sim 654$ & Hakuchi \\
$686 \sim$ & Shuchô \\
$701 \sim 704$ & Daihô \\
$704 \sim 708$ & Kyoun \\
$708 \sim 715$ & Wadô \\
$715 \sim 717$ & Reiki \\
$717 \sim 724$ & Yorô \\
$724 \sim 729$ & Jinki \\
$729 \sim 749$ & Tenpyô \\
$749 \sim$ & Tenpyô Kan'hô \\
$749 \sim 757$ & Tenpyô Shôhô \\
$757 \sim 765$ & Tenpyô Hôji \\
$765 \sim 767$ & Tenpyô Jingo \\
$767 \sim 770$ & Jingo Keiun \\
$770 \sim 781$ & Hôki \\
$781 \sim 782$ & Ten'ô \\
$782 \sim 806$ & Enryaku
\end{tabular}

$\begin{array}{ll}806 \sim 810 & \text { Daidô } \\ 810 \sim 824 & \text { Kônin } \\ 824 \sim 834 & \text { Tenchô } \\ 834 \sim 848 & \text { Shôwa } \\ 848 \sim 851 & \text { Kashô } \\ 851 \sim 854 & \text { Ninju } \\ 854 \sim 857 & \text { Saikô } \\ 857 \sim 859 & \text { Ten'an } \\ 859 \sim 877 & \text { Jôgan } \\ 877 \sim 885 & \text { Gangyô } \\ 885 \sim 889 & \text { Nin'na } \\ 889 \sim 898 & \text { Kanbei } \\ 898 \sim 901 & \text { Shôtai } \\ 901 \sim 923 & \text { Engi } \\ 923 \sim 931 & \text { Enchô } \\ 931 \sim 938 & \text { Shôhei } \\ 938 \sim 947 & \text { Tenkyô } \\ 947 \sim 957 & \text { Tenryaku }\end{array}$

(4) SANSEIDÔ, ed. Nihon Bunkashi Nenpyô, "Tabela cronológica da História da Cultura Japonesa" In: Shinmeikaku Kogo Jiten, "Novo Dicionário Explicativo da Língua Clássica" Tóquio, Sanseidô, 1978, pp. $1242-1247$. 


\begin{tabular}{|c|c|c|c|}
\hline $957 \sim 961$ & Tentoku & $1113 \sim 1118$ & Eikyû \\
\hline $961 \sim 964$ & Ôwa & $1118 \sim 1120$ & Gen'ei \\
\hline $964 \sim 968$ & Kôhô & $1120 \sim 1124$ & Hôan \\
\hline $968 \sim 970$ & An'na & $1124 \sim 1126$ & Tenji \\
\hline $970 \sim 973$ & Tenroku & $1126 \sim 1131$ & Daiji \\
\hline $973 \sim 976$ & Ten'en & $1131 \sim 1132$ & Tenshô \\
\hline $976 \sim 978$ & Jôgen & $1132 \sim 1135$ & Chôshô \\
\hline $978 \sim 983$ & Tengen & $1135 \sim 1141$ & Hôen \\
\hline $983 \sim 985$ & Eikan & $1141 \sim 1142$ & Eiji \\
\hline $985 \sim 987$ & Kan'na & $1142 \sim 1144$ & Kôji \\
\hline $987 \sim 989$ & Eien & $1144 \sim 1145$ & Tenyô \\
\hline $989 \sim 990$ & Eiso & $1145 \sim 1151$ & Kyûan \\
\hline $990 \sim 995$ & Shôryaku & $1151 \sim 1154$ & Ninbyô \\
\hline $995 \sim 999$ & Chôtoku & $1154 \sim 1156$ & Kyûju \\
\hline $999 \sim 1004$ & Chôhô & $1156 \sim 1159$ & Hôgen \\
\hline $1004 \sim 1012$ & Kankô & $1159 \sim 1160$ & Heiji \\
\hline $1012 \sim 1017$ & Chôwa & $1160 \sim 1161$ & Eiryaku \\
\hline $1017 \sim 1021$ & Kan'nin & $1161 \sim 1163$ & Ôhô \\
\hline $1021 \sim 1024$ & Jian & $1163 \sim 1165$ & Chôkan \\
\hline $1024 \sim 1028$ & Manju & $1165 \sim 1166$ & Eiman \\
\hline $1028 \sim 1037$ & Chôgen & $1166 \sim 1169$ & Nin'an \\
\hline $1037 \sim 1040$ & Chôryaku & $1169 \sim 1171$ & Kaô \\
\hline $1040 \sim 1044$ & Chôkyû & $1171 \sim 1175$ & Shôan \\
\hline $1044 \sim 1046$ & Kantoku & $1175 \sim 1177$ & Angen \\
\hline $1046 \sim 1053$ & Eishô & $1177 \sim 1181$ & Jishô \\
\hline $1053 \sim 1058$ & Tengi & $1181 \sim 1182$ & Yôwa \\
\hline $1058 \sim 1065$ & Kôhei & $1182 \sim 1185$ & Juei \\
\hline $1065 \sim 1069$ & Jiryaku & $1184 \sim$ & Genryaku \\
\hline $1069 \sim 1074$ & Enkyû & $1185 \sim 1190$ & Bunji \\
\hline $1074 \sim 1077$ & Shôhô & $1190 \sim 1199$ & Kenkyû \\
\hline $1077 \sim 1081$ & Shôryaku & $1199 \sim 1201$ & Shôji \\
\hline $1081 \sim 1084$ & Eihô & $1201 \sim 1204$ & Ken'nin \\
\hline $1084 \sim 1087$ & Ôtoku & $1204 \sim 1206$ & Genkyû \\
\hline $1087 \sim 1094$ & Kanji & $1206 \sim 1207$ & Ken'ei \\
\hline $1094 \sim 1096$ & Kahô & $1207 \sim 1211$ & Shôgen \\
\hline $1096 \sim 1097$ & Eichô & $1211 \sim 1213$ & Kenryaku \\
\hline $1097 \sim 1099$ & Shôtoku & $1213 \sim 1219$ & Ken'hô \\
\hline $1099 \sim 1104$ & Kôwa & $1219 \sim 1222$ & Shôkyû \\
\hline $1104 \sim 1106$ & Chôji & $1222 \sim 1224$ & Jôô \\
\hline $1106 \sim 1108$ & Kashô & $1224 \sim 1225$ & Gen'nin \\
\hline $1108 \sim 1110$ & Ten'nin & $1225 \sim 1227$ & Karoku \\
\hline $1110 \sim 1113$ & Ten'ei & $1227 \sim 1229$ & Antei \\
\hline
\end{tabular}




\begin{tabular}{|c|c|c|c|}
\hline $1229 \sim 1232$ & Kangi & $1346 \sim 1370$ & Shôhei \\
\hline $1232 \sim 1233$ & Jôei & $(1350 \sim 1352)$ & Kan'ô \\
\hline $1233 \sim 1234$ & Tenfuku & $(1352 \sim 1356)$ & Bunwa \\
\hline $1235 \sim 1238$ & Katei & $(1356 \sim 1361)$ & Enbun \\
\hline $1238 \sim 1239$ & Ryakunin & $(1361 \sim 1362)$ & Kôan \\
\hline $1239 \sim 1240$ & En'ô & $(1362 \sim 1368)$ & Jôji \\
\hline $1240 \sim 1243$ & Ninji & $(1368 \sim 1375)$ & Ôan \\
\hline $1243 \sim 1247$ & Kangen & $1370 \sim 1372$ & Kentoku \\
\hline $1247 \sim 1249$ & Hôji & $1372 \sim 1375$ & Bunchû \\
\hline $1249 \sim 1256$ & Kenchô & $1375 \sim 1381$ & Tenjû \\
\hline $1256 \sim 1257$ & Kôgen & $(1375 \sim 1379)$ & Eiwa \\
\hline $1257 \sim 1259$ & Shôka & $(1379 \sim 1381)$ & Kôryaku \\
\hline $1259 \sim 1260$ & Shôgen & $1381 \sim 1384$ & Kôwa \\
\hline $1260 \sim 1261$ & Bun'ô & $(1381 \sim 1384)$ & Eitoku \\
\hline $1261 \sim 1264$ & Kôchô & $1384 \sim 1392$ & Genchû \\
\hline $1264 \sim 1275$ & Bun'ei & $(1384 \sim 1387)$ & Shitoku \\
\hline $1275 \sim 1278$ & Kenji & $(1387 \sim 1389)$ & Kakei \\
\hline $1278 \sim 1288$ & Kôan & $(1389 \sim 1390)$ & Kôô \\
\hline $1288 \sim 1293$ & Shôô & $(1390 \sim 1392)$ & Meitoku \\
\hline $1293 \sim 1299$ & Einin & $1392 \sim 1394$ & Meitoku \\
\hline $1299 \sim 1302$ & Shôan & $1394 \sim 1428$ & Ôei \\
\hline $1302 \sim 1303$ & Kengen & $1428 \sim 1429$ & Shôchô \\
\hline $1303 \sim 1306$ & Kagen & $1429 \sim 1441$ & Eikyô \\
\hline $1306 \sim 1308$ & Tokuji & $1441 \sim 1444$ & Kakichi \\
\hline $1308 \sim 1311$ & Enkyô & $1444 \sim 1449$ & Bun'an \\
\hline $1311 \sim 1312$ & Ôchô & $1449 \sim 1452$ & Hôtoku \\
\hline $1312 \sim 1317$ & Shôwa & $1452 \sim 1455$ & Kyôtoku \\
\hline $1317 \sim 1319$ & Bun'hô & $1455 \sim 1457$ & Kôshô \\
\hline $1319 \sim 1321$ & Gen'ô & $1457 \sim 1460$ & Chôroku \\
\hline $1321 \sim 1324$ & Genkô & $1460 \sim 1466$ & Kanshô \\
\hline $1324 \sim 1326$ & Shôchû & $1466 \sim 1467$ & Bunshô \\
\hline $1326 \sim 1329$ & Karyaku & $1467 \sim 1469$ & Ônin \\
\hline $1329 \sim 1331$ & Gentoku & $1469 \sim 1487$ & Bunmei \\
\hline $1331 \sim 1334$ & Genkô & $1487 \sim 1489$ & Chôkyô \\
\hline$(1332 \sim 1334)$ & Shôkyô & $1489 \sim 1492$ & Entoku \\
\hline $1334 \sim 1336$ & Kenmu & $1492 \sim 1501$ & Meiô \\
\hline $1336 \sim 1340$ & Engen & $1501 \sim 1504$ & Bunki \\
\hline$(1336 \sim 1338)$ & Kenmu & $1504 \sim 1521$ & Eishô \\
\hline$(1338 \sim 1342)$ & Ryakuô & $1521 \sim 1528$ & Daiei \\
\hline $1340 \sim 1346$ & Kôkoku & $1528 \sim 1532$ & Kyôroku \\
\hline$(1342 \sim 1345)$ & Kôei & $1532 \sim 1555$ & Tenbun \\
\hline$(1345 \sim 1350)$ & Jôwa & $1555 \sim 1558$ & Kôji \\
\hline
\end{tabular}




\begin{tabular}{ll||rl}
$1558 \sim 1570$ & Eiroku & $1736 \sim 1741$ & \\
$1570 \sim 1573$ & Genki & $1741 \sim 1744$ & Genbun \\
$1573 \sim 1592$ & Tenshô & $1744 \sim 1748$ & Enkyô \\
$1592 \sim 1596$ & Bunroku & $1748 \sim 1751$ & Kan'en \\
$1596 \sim 1615$ & Keichô & $1751 \sim 1764$ & Hôreki \\
$1615 \sim 1624$ & Gen'na & $1764 \sim 1772$ & Meiwa \\
$1624 \sim 1644$ & Kan'ei & $1772 \sim 1781$ & An'ei \\
$1644 \sim 1648$ & Shôhô & $1781 \sim 1789$ & Tenmei \\
$1648 \sim 1652$ & Keian & $1789 \sim 1801$ & Kansei \\
$1652 \sim 1655$ & Shôô & $1801 \sim 1804$ & Kyôwa \\
$1655 \sim 1658$ & Meireki & $1804 \sim 1818$ & Bunka \\
$1658 \sim 1661$ & Manji & $1818 \sim 1830$ & Bunsei \\
$1661 \sim 1673$ & Kanbun & $1830 \sim 1844$ & Tenpô \\
$1673 \sim 1681$ & En'hô & $1844 \sim 1848$ & Kôka \\
$1681 \sim 1684$ & Ten'na & $1848 \sim 1854$ & Kaei \\
$1684 \sim 1688$ & Jôkyô & $1854 \sim 1860$ & Ansei \\
$1688 \sim 1704$ & Genroku & $1860 \sim 1861$ & Man'en \\
$1704 \sim 1711$ & Hôei & $1861 \sim 1864$ & Bunkyû \\
$1711 \sim 1716$ & Shôtoku & $1864 \sim 1865$ & Genji \\
$1716 \sim 1736$ & Kyôhô & $1865 \sim 1868$ & Keiô
\end{tabular}

No Japão, o primeiro período registrado conforme esse sistema é o Período Taika $(654 \sim 650)$. Como entre o Período Taika e o Período Daihô existe certa irregularidade, houve época em que considerava-se como primeiro nengô, o Período Daihô, porque a partir deste período, o nengô foi utilizado sem interrupções até o Período Meiji. Não houve mais divisões em nengô a partir da Restauração Meiji, mas isso não quer dizer que esse sistema tenha sido esquecido. Os nengô aparecem frequientemente entre parênteses, ao lado de uma data(5).

\section{PERIOdIZAÇÃO NA HISTÓRIA DA CULTURA E LITERATURA JA- PONESAS}

Aqui é necessário fazer uma distinção entre o objeto da História do Japão propriamente dita e o objeto da História da Cultura Japonesa.

A História do Japão normalmente aborda vários aspectos da vida de uma nação em determinadas épocas, isto é, o aspecto político, econômico social e cultural, e dentro disso, os aspectos políticos e econômicos parecem ser mais enfatizados.

(5) Por exemplo: "A queda do Shogunato Kamakura foi em 1333 (Genkô 3)"; isto quer dizer que o fato se deu no ano 3 do Período Genkô. 
A História da Cultura tem uma área mais restrita; seu objeto de estudo é a cultura e dentro da cultura estão em geral incluídos fatos ligados às artes em geral, à religião e à educação.

A grosso modo, podemos dizer que os aspectos políticos, econômicos e sociais fazem parte do objeto da História do Japão propriamente dita.

A História da Cultura Japonesa possue sua própria periodização que é distinta da periodização baseada em critérios políticos. A interligação entre as duas periodizações é bastante evidente pois de certo modo a periodização cultural acompanha a evolução política (Ver Tabela 2).

\section{TABELA 2 - PERIODIZAÇÃO CULTURAL}

\begin{tabular}{|c|c|}
\hline Bunka "Cultura" & Jidai "Período" \\
\hline Kyûsekki Bunka & Kyûsekki Jidai \\
\hline Jômon Bunka & Jômon Jidai \\
\hline Yayoi Bunka & Yayoi Jidai \\
\hline Kofun Bunka fim do séc. $3 \sim$ fim do séc. 7 . & Yamato Jidai \\
\hline $\begin{array}{ll}\text { Asuka Bunka fim do séc. } 6 \sim \text { meados do } \\
\text { séc. } 7\end{array}$ & Yamato Jidai \\
\hline $\begin{aligned} \text { Hakuhô Bunka - } & 2 \text { a metade do séc. } 7 \sim \\
& \text { início do séc. } 8 .\end{aligned}$ & Yamato/Nara Jidai \\
\hline Tenpyô Bunka - séc. 8 & Nara Jidai \\
\hline Kônin-Jôgan Bunka - séc. 9 & Heian Jidai \\
\hline Fujiwara Bunka - séc. $10 \sim$ séc. 11 & Heian Jidai \\
\hline Kamakura Bunka - séc. $12 \sim$ séc. 14 & Kamakura Jidai \\
\hline Kitayama Bunka - séc. $14 \sim$ séc. 15 & Muromachi Jidai \\
\hline Higashiyama Bunka - séc. 15 & Muromachi Jidai \\
\hline Azuchi-Momoyama Bunka - séc. $16 \sim$ séc. 17 & Azuchi-Momoyama Jidai \\
\hline Genroku Bunka - séc. $17 \sim$ séc. 18 & Edo fidai \\
\hline Kasei Bunka séc. 19 & Edo Jidai \\
\hline Meiji Bunka séc. $19 \sim$ séc. 20 (1912) & Meiji Jidai \\
\hline Taishô Bunka - 1912 1926 & Taishô Jidai \\
\hline Shôwa Bunka - 1926 & Shôwa Jidai \\
\hline
\end{tabular}


Existe uma outra periodização que é utilizada nos estudos sobre História da Literatura Japonesa. Esta periodização, como veremos a seguir também tem uma forte ligação com a história política.

A História da Literatura Japonesa pode ser dividida da seguinte forma:

1) Jôdai Bungaku "Literatura Jôdai" (711 794) - é a literatura do período em que a capital era em Yamato. Por isso também é conhecida como Yamato Bungaku.

2) Chûko Bungaku "Literatura Chûko" (794 1156) - também chamada Kyôto Bungaku, por se tratar da literatura do período em que a sede política era em Kyôto.

3) Chûsei Bungaku "Literatura Chûsei" (1156 1561) - pode ser dividida em:
a) Kamakura Bungaku - $1156 \sim 1334$.
b) Yoshino Bungaku - $1334 \sim 1392$ (ver parágrafo 3.3.2).
c) Muromachi Bungaku - $1392 \sim 1560$.

4) Kinsei Bungaku "Literatura Kinsei" (1560 1868) - divide-se em:

a) Azuchi-Momoyama Bungaku - $1560 \sim 1614$.

b) Kamigata Bungaku - $1614 \sim 1736$.

c) Bunka Tôsenki Bungaku - $1736 \sim 1804$.

d) Edo Bungaku - $1804 \sim 1868$.

5) Kindai Bungaku "Literatura Kindai" (1868 1926) - divide-se em:

a) Meiji Bungaku - $1868 \sim 1912$.

b) Taishô Bungaku - $1912 \sim 1926$.

6) Gendai Bungaku "Literatura Gendai" (1926 ) - refere-se à literatura do Período Shôwa, denominada Shôwa Bungaku.

\section{FUNÇÃO E VALOR DA PERIOdIZAÇÃO}

Diante de tais divisões, subdivisões e subdivisões de subdivisões, poderíamos a princípio achar que tudo seria mais fácil se não houvesse tantos nomes para serem lembrados. Na realidade isto está bem longe da verdade; fixar o nome de eras e períodos pode ser penoso no início mas é muito mais prático do que decorar uma lista de datas. A periodização facilita muito o trabalho do pesquisador, pois permite que o interessado selecione e delimite sua área de interesse.

Porém, ainda que alguém não concorde com a afirmação de que o sistema de divisão histórica japonesa é prático, ainda sim teria que conhecê-lo porque os nomes das eras e períodos até aqui relacionados, são largamente usados não só nos livros de história mas em livros de outras áreas do conhecimento. 
Além disso, existe um outro lado da questão. A divisão histórica japonesa merece ser apreciada como algo que tem valor por si só, pois ela é única, ou seja, só diz respeito à história japonesa. Talvez seja por esse motivo que o nengô é preservado até hoje. Afinal sendo único, é precioso como qualquer tesouro histórico nacional.

\section{BIBLIOGRAFIA}

HACA, Kôshiro, ed., Nihonshi Jiten "Dicionário de História do Japão" Tóquio, Iwasaki Shoten, 1957.

HALL, John Whitney. Japan from Prehistory to Modern Times. Tóquio, Charles E. Tuttle Company, 1979.

HISAMATSU, Sen'ichi. Nihon Bungakushi Tsûsetsu-yori "História da Literatura Japonesa uma visão geral" Tóquio, Yûhikakusôsho, 1979.

ISHIDA, Ichirô. Nihon Bunkashi Gairon "Introdução à História da Cultura Japonesa". Tóquio, Ishikawa Hirofumi-kan, 1971.

MIYASAKI, Ichisada \& ONO, Shinji. Nengô, "Nengô" In: Dai Nippon Hyakkajiten, "Encyclopedia Japonica", v. 14. Tóquio, Shôgakkan, 1973, pp. 266-267.

NIHONSHI YÔCO DAIIITEN HENSHÛIINKAl, ed. Nihonshi Yôgo Daijiten, "Dicionário de termos da História do Japão", v. 2. Tóquio, Nihonshi Yôgo Daijiten Henshûiinkai, 1978, pp. 986-989.

ONABE, Teruhiko. Jidai Kubun, "Divisão histórica" In: Sekkai Daihyakkajiten, "Enciclopédia Universal", v. 13. Tóquio, Heibonsha, 1972, p. 272.

ONO, Shinji. Nihon-ni okeru Jidai Kubun, "Divisão histórica no Japão" In: Dai Nippon Hyakkajiten, "Encyclopedia Japonica", v. 8. Tóquio, Shôgakkan, 1972, p. 545.

SANSEIDÔ HENSHÛJO (Editora Sanseidô). Nihonshi Shôjiten, "Pequeno Dicionário de História do Japão". Tóquio, Sanseidô Co., Ltd., 1974.

SHIMOMURA, Fujio. Nihonshi Seigi, "História do Japão comentada" Tóquio, Baifûkan, 1965.

TAKEUCHI, Massami et al. Shin Nihonshi, "Nova História do Japão". Tóquio Jiyû Shobô, 1978. 